\title{
REMEDIES OVER THE OBSTACLES IN IMPLEMENTING AUTOMATION IN INDIAN INFRASTRUCTURE PROJECTS
}

\author{
Akash S. Tambi ${ }^{1}$, Atul R. Kolhe ${ }^{2}$, Upendra Saharkar ${ }^{3}$ \\ ${ }^{I}$ M.E. (Construction and Management) Pursuing, Civil Department, Dr. D.Y.Patil Institute of Engineering and \\ Technology, Ambi, Talegaon, Pune, Maharashtra, India \\ ${ }^{2}$ Head of the Department, Civil Department, Dr.D.Y.Patil School of Engineering, Lohagaon, Pune, Maharashtra, \\ India \\ ${ }^{3}$ P.G. Coordinator, Civil Department, Dr. D.Y.Patil Institute of Engineering and Technology, Ambi, Talegaon, Pune, \\ Maharashtra, India
}

\begin{abstract}
Infrastructure project requires more number of skilled labour, good quality of work, increases productivity etc. for this purpose we use automation technologies. The construction industry is labour intensive and construction work is conducted in dangerous and risky situation. So, we have to use different automation technology. There are so many obstacles while implementing automation technologies. Some of them are high cost of automation technologies, maintenance and operating cost, skilled worker, knowledge about automation to worker, availability of technologies etc. The automation technologies are so expensive and has greater obstacles to implement cost of automation is the major factor whether to consider or not, technology for the construction work. These technologies are not easily accepted by worker because of less knowledge about automation. This paper describes the remedies over the obstacles in implementing automation technologies.
\end{abstract}

Keywords: Automation, Advantages, Obstacles, Remedies.

\section{INTRODUCTION}

Infrastructure project is growing very largely in India. For this we have to implement automation technologies to increase the productivity, safety, quality etc. The unskilled human resources are unable to give good quality of work as compared to automated technology.

"Automation can be defined as appropriate use of machines, electronic devices and computer software for the construction work to increase the productivity of construction project, reduces the duration and laborious work, and increases the construction safety."

Automation of construction activities has always been challenging. The key challenge arises from the fact that construction unlike manufacturing is usually done in an unstructured fashion. Automation technology available has not been adequate to meet the needs of such unstructured environment. In India, automation technology is less adopted as compared to other countries. In developed countries such as Japan, Germany the use of automation, developing the techniques and implementing automation are as good as compared to developing countries such as India and China. In this paper, the main objective is to discuss the obstacles and remedies over the obstacles while implementing automation technologies in Indian infrastructure projects.

\section{ADVANTAGES OF AUTOMATION}

The project success from the project management's viewpoint is achieved when the project is completed with the lowest possible cost, the highest quality, no accidents etc. In other words, success means bringing each of the project performance indicator (PPI) such as cost, schedule, quality, safety, labour, productivity, material consumption or waste, etc. to an optimum values.

The advantages of automation in infrastructure projects are as follows:

i. Higher safety for both worker and public through developing and deploying machines for dangerous jobs.

ii. Uniform quality with higher accuracy than that provided by skilled worker.

iii. Improving work environment as conventional manual work is reduced to minimum, so the workers are relieved from uncomfortable work positions.

iv. Eliminating complains about noise and dust concerning works such as removal, cleaning or preparation of surfaces.

v. Increasing productivity and work efficiency with reduced costs.

\section{OBSTACLES}

The obstacles while implementing automation technologies in Indian infrastructure projects are as follows:- 


\subsection{High Cost}

The cost of automation technology is so high to implement. In infrastructure projects, cost consideration should include the purchasing cost. Due to high cost very less users use the automation technology.

\subsection{Limited Resource Available to Small and Medium Size Firms:}

For small and medium size firm limited resource should be available. The funding available is less for the small and medium size firm.

\subsection{Automation Technologies are Expensive to}

\section{Update and Maintain}

Cost consideration should include not only the purchasing cost, but also the maintaining the automation technologies. These techniques are so expensive to update and maintain the progress of automation techniques.

\subsection{Automation Technologies are Unavailable}

\section{Locally or Difficult to Acquire}

Implementation of automation may be a problem if the technology is not readily available commercially or is difficult to acquire because of some restrictions or other.

\subsection{Low Technological Knowledge to Workers}

This is the main obstacle during implementing automation technology. There are so many unskilled labor in India. They have no knowledge about automation technology.

\section{REMEDIES}

Remedies over the obstacles while implementing automation technologies in Indian infrastructure projects are as follows

\subsection{Remedies over High Cost:}

The high cost is main obstacles in implementing automation. The automation technology is so expensive. The infrastructure construction company should apply the automation technology for greater productivity and good quality of work. The company should take loan from World Bank at low interest to implement the automation technology. Indian Infrastructure Company should take loan from World Bank and Reserve Bank of India at low interest to proper implementation of automation technology. Government incentives should be given to contractors, builders and infrastructure companies for using innovative approaches to construction.

\subsection{Remedies over Limited Resource Available to}

\section{Small and Medium Size Firms}

For small and medium size firms the resource should be available for using automation technology is less. The funds available for implementing automation technology are less as compared to big construction companies. To overcome from improper funding companies should tie up to other companies to implement automation technology. They should form joint ventures to purchase the automated technologies and use this automated technology together.

\subsection{Remedies over Automation Technologies are}

\section{Expensive to Update and Maintain}

The remedies over automation technologies to update and maintain are getting loan from World Bank and the automation should be properly used and maintained. The automation technology should be updated and maintained tie to time for proper working operation. It should increases the productivity of machines or project.

\subsection{Remedies over Automation Technologies are} Unavailable Locally or Difficult to Acquire

The automation technologies are unavailable locally or difficult to acquire, the company should get in joint ventures with company uses this automated technologies and get the technology from somewhere else.

\subsection{Remedies over low technological knowledge to workers}

The technologies are not as easily accepted by worker. They have no knowledge about automation technologies. Considering the re-training of construction workers, to supervise maintain and programmed the technologies are not seen as a way to replace the worker. The training can be incorporated through a set of necessary upgrading skills for semi-skilled worker or through seminars and workshops. Change in education and training of construction professionals, this is relevant if there is to be increased understanding of the technologies in the industry and on the worksites.

\section{CONCLUSIONS AND RECOMMENDATIONS}

As the main objective of this paper is to state remedies over the obstacles in implementing automation technologies in Indian Infrastructure Projects and Construction Firms. Remedies over different obstacles are seen above. Small and medium size firms are encouraging to adopt automation technologies. They give information or training to labour to operate automation technologies. The funding on loan should be available from World Bank and Reserve Bank of India at low interest rate to implement new innovative technology in construction and infrastructure projects.

\section{REFERENCES}

[1]. K. Sandeep Kumar, 'Advanced Construction and Building Technology: Automation, Robotics, Services.' (International Journal of Advance Scientific Research and Technology) pg.277-285. (April 2012). 
[2]. Matt M. Hewitt and John A. Gambatese, 'Automation Consideration during Project Design.' Proceeding of International Symposium on Automation and Robotics in Construction, Washington D.C. 2002.

[3]. Li-Ren Yang and James T. O'connor, 'Assessment of Automation and Integration Technology's Impacts on Project Stakeholder success. Automation in Construction 16 (2007) 725-733.

[4]. Shinko Research Co. Ltd, 'Automation of Building Construction and Building Product Industry- State of Art in Japan. Dec.18 2007.

[5]. Thomas Bock, 'Hybrid Construction Automation and Robotics, International Symposium on Automation and Robotics in Construction 2007 India.

[6]. S.M.S. Elattar, 'Automation and Robotics in Construction, Opportunities and Challenges (Emirates Journal for Engineering Research) (2008), Vol. 13(2),p. 21 26

[7]. Mohan Ramanathan, 'Concept to Position and Enhance Automation Technologies in Emerging Construction Markets' (International Symposium on Automation and Robotics in Construction 2007) p. 11-16

\section{BIOGRAPHIES}

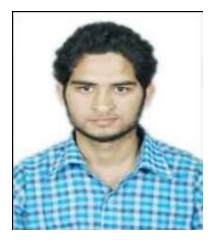

Akash Santosh Tambi was born in 1990 in Amravati District, Maharashtra. He received his Bachelor of Engineering Degree in Civil Engineering from Prof. Ram Meghe Institute of Technology and Research Centre, Amravati University in 2012. He has pursuing his Master's Degree in Construction and Management from Dr. D.Y. Patil Institute of Engineering and Technology, Ambi, Pune, University. 